\title{
Article
}

\section{Establishment of Intestinal Organoid from Rousettus leschenaultii and the Susceptibility to Bat-Associated Viruses, SARS-CoV-2 and Pteropine Orthoreovirus}

\author{
Mohamed Elbadawy ${ }^{1,2,+}{ }^{D}$, Yuki Kato ${ }^{3,+}$, Nagisa Saito ${ }^{3}$, Kimika Hayashi ${ }^{1}$, Amira Abugomaa ${ }^{1,4}$ (D), \\ Mio Kobayashi ${ }^{5}$, Toshinori Yoshida ${ }^{5}$, Makoto Shibutani ${ }^{5}(\mathbb{D})$, Masahiro Kaneda ${ }^{6} \mathbb{D}^{\circ}$, Hideyuki Yamawaki $^{7}$, \\ Tetsuya Mizutani ${ }^{3}{ }^{D}$, Chang-Kweng Lim ${ }^{8} \mathbb{D}$, Masayuki Saijo ${ }^{8} \mathbb{D}$, Kazuaki Sasaki ${ }^{1}$, Tatsuya Usui ${ }^{1, *}$ \\ and Tsutomu Omatsu ${ }^{3, *}$
}

check for updates

Citation: Elbadawy, M.; Kato, Y.; Saito, N.; Hayashi, K.; Abugomaa, A.; Kobayashi, M.; Yoshida, T.; Shibutani, M.; Kaneda, M.; Yamawaki, H.; et al. Establishment of Intestinal Organoid from Rousettus leschenaultii and the Susceptibility to Bat-Associated Viruses, SARS-CoV-2 and Pteropine Orthoreovirus. Int. J. Mol. Sci. 2021, 22, 10763. https://doi.org/10.3390/ ijms221910763

Academic Editors: Julie Bouckaert, Keijo Viiri and Kati Juuti-Uusitalo

Received: 26 July 2021

Accepted: 28 September 2021

Published: 5 October 2021

Publisher's Note: MDPI stays neutral with regard to jurisdictional claims in published maps and institutional affiliations.

Copyright: (c) 2021 by the authors. Licensee MDPI, Basel, Switzerland. This article is an open access article distributed under the terms and conditions of the Creative Commons Attribution (CC BY) license (https:// creativecommons.org/licenses/by/ $4.0 /)$.
1 Laboratory of Veterinary Pharmacology, Department of Veterinary Medicine, Faculty of Agriculture, Tokyo University of Agriculture and Technology, 3-5-8 Saiwai-cho, Fuchu, Tokyo 183-8509, Japan; Mohamed.elbadawy@fvtm.bu.edu.eg (M.E.); s156174y@st.go.tuat.ac.jp (K.H.); s193249s@st.go.tuat.ac.jp (A.A.); skazuaki@cc.tuat.ac.jp (K.S.)

2 Department of Pharmacology, Faculty of Veterinary Medicine, Benha University, Moshtohor, Toukh 13736, Elqaliobiya, Egypt

3 Center for Infectious Diseases of Epidemiology and Prevention Research, Tokyo University of Agriculture and Technology, 3-5-8 Saiwai-cho, Fuchu, Tokyo 183-8509, Japan; s163602q@st.go.tuat.ac.jp (Y.K.); s176469x@st.go.tuat.ac.jp (N.S.); tmizutan@cc.tuat.ac.jp (T.M.)

4 Faculty of Veterinary Medicine, Mansoura University, Mansoura 35516, Dakahliya, Egypt

5 Laboratory of Veterinary Pathology, Department of Veterinary Medicine, Faculty of Agriculture, Tokyo University of Agriculture and Technology, 3-5-8 Saiwai-cho, Fuchu, Tokyo 183-8509, Japan; s212838s@st.go.tuat.ac.jp (M.K.); yoshida7@cc.tuat.ac.jp (T.Y.); mshibuta@cc.tuat.ac.jp (M.S.)

6 Laboratory of Veterinary Anatomy, Department of Veterinary Medicine, Faculty of Agriculture, Tokyo University of Agriculture and Technology, 3-5-8 Saiwai-cho, Fuchu, Tokyo 183-8509, Japan; kanedam@cc.tuat.ac.jp

7 Laboratory of Veterinary Pharmacology, School of Veterinary Medicine, Kitasato University, 35-1, Higashi 23 Ban-cho, Towada, Aomori 034-8628, Japan; yamawaki@vmas.kitasato-u.ac.jp

8 Department of Virology I, National Institute of Infectious Diseases, Toyama 1-23-1, Shinjuku, Tokyo 162-8640, Japan; ck@nih.go.jp (C.-K.L.); msaijo@nih.go.jp (M.S.)

* Correspondence: fu7085@go.tuat.ac.jp (T.U.); tomatsu@cc.tuat.ac.jp (T.O.); Tel./Fax: +81-42-367-5770 (T.U.); +81-42-367-5744 (T.O.)

$+\quad$ These authors contributed equally to this work.

Abstract: Various pathogens, such as Ebola virus, Marburg virus, Nipah virus, Hendra virus, Severe Acute Respiratory Syndrome Coronavirus (SARS-CoV), Middle East Respiratory Syndrome Coronavirus (MERS-CoV), and SARS-CoV-2, are threatening human health worldwide. The natural hosts of these pathogens are thought to be bats. The rousette bat, a megabat, is thought to be a natural reservoir of filoviruses, including Ebola and Marburg viruses. Additionally, the rousette bat showed a transient infection in the experimental inoculation of SARS-CoV-2. In the current study, we established and characterized intestinal organoids from Leschenault's rousette, Rousettus leschenaultii. The established organoids successfully recapitulated the characteristics of intestinal epithelial structure and morphology, and the appropriate supplements necessary for long-term stable culture were identified. The organoid showed susceptibility to Pteropine orthoreovirus (PRV) but not to SARS-CoV-2 in experimental inoculation. This is the first report of the establishment of an expandable organoid culture system of the rousette bat intestinal organoid and its sensitivity to bat-associated viruses, PRV and SARS-CoV-2. This organoid is a useful tool for the elucidation of tolerance mechanisms of the emerging rousette bat-associated viruses such as Ebola and Marburg virus.

Keywords: bat; natural host; organoid; long-term stable culture; virus susceptibility; SARS-CoV-2; ACE2; TMPRSS2 


\section{Introduction}

Bats are one of the most important natural reservoirs for a variety of emerging viruses that induce severe illness, including severe acute respiratory syndrome coronavirus (SARS$\mathrm{CoV}$ ), Middle East respiratory syndrome coronavirus (MERS-CoV), Hendra virus, Ebola virus, Marburg virus, and SARS-CoV-2 [1-4]. Among the Rousettus spp., the rousette bat is thought to be a natural reservoir of Ebola and Marburg viruses (family Filoviridae) and is a source of virus spillover into human populations; these viruses have frequently caused outbreaks in African countries [5,6]. These days, betacoronavirus genome [7,8] and CoV RNA-dependent RNA polymerase gene [9] were also detected in Rousettus spp. The susceptibility of Rousettus aegyptiacus to SARS-CoV-2 infection was tested, and it was revealed that $78 \%$ of the inoculated bats had a transient infection with detection of SARSCoV-2 RNA in their lung, lung-associated lymphatic tissue, and trachea [10]. The infected fruit bats were also able to spread the virus to contact bats leading to infection [10]. IgG against Ebola virus and Reston virus was detected in Rousette aegyptiacs, R. amplexicaudatus, and $R$. leschenaultii [11-13]. In an experiment involving inoculation of $R$. aegyptiacs with Marburg virus, viremia was detected, and a systemic infection developed without any symptoms [14].

Pteropine orthoreovirus (PRV) was a causative agent of respiratory disease in Humans. PRV was first isolated in 1968 from Pteropus poliocephalus [15], and then, PRV has been detected in patients with respiratory illness and isolated from several species of flying foxes including R. amplexicaudatus and R. leschenaultii in South East Asia and Australia [16-20]. Thus, rousette bats are a natural reservoir for a variety of pathogens that cause serious diseases in humans. However, there are limitations in using individual bats to analyze the virus tolerance mechanism in the body in detail.

Knowledge of the bat-specific immune response against virus infection at the organ level has been restricted by the limitations of the in vitro system. Three-dimensional culture systems, such as organoids, have been established and used to study disease modeling, drug testing, stem cell behavior, and epithelial responses to injury and host-pathogen interactions in humans and mice [21-28].

The intestinal tract is known to be one of the gateways for pathogens to enter and exit the body, along with the lungs, and expression of angiotensin-converting enzyme II (ACE2), the receptor of SARS-CoV and SARS-CoV-2, was identified within intestinal tissue with the same level as lung in Egyptian rousette bat [29]. In bats, intestinal organoids from Rhinolophu sinicus, a natural reservoir of SARS-CoV, were established, and it was shown that the organoids recapitulated the bat intestinal epithelium [30]. These horseshoe bat enteroids express ACE2 and transmembrane cellular protease serine 2 (TMPRSS2). The bat enteroids developed an cytopathic effect (CPE), and increased viral load was observed until $72 \mathrm{~h}$ post-infection. However, the investigators could not consistently sustain long-term expansion, as in human enteroids, using their medium cocktail.

Novel in vitro experimental systems are necessary to analyze virus-host interactions in fruit bats against Ebola and Marburg viruses and to isolate novel viruses from fruit bats. Therefore, we aimed to establish and characterize intestinal organoids from $R$. leschenaultii, assess long-term culture methods, and evaluate their usefulness for studying host-virus interactions.

\section{Results}

\subsection{Establishment of Intestinal Organoid from Rousettus leschenaultii}

Rousette bat intestinal organoids were successfully generated and analysed from $R$. leschenaultii that died of natural causes at the zoo and were collected Figure 1A. The structure of the organoid mimicked the multicellular structure of the bat small intestinal epithelium (Figure 1B), and the organoids recapitulated the histology of the original tissue (Figure 1C). In TEM analysis, the ultrastructural morphology of organoids mimicked that of intestinal tissues. The absorptive epithelial cells with characteristics of microvilli, goblet cells, and Paneth cells were identified in the organoids (Figure 1D). 


\section{A}

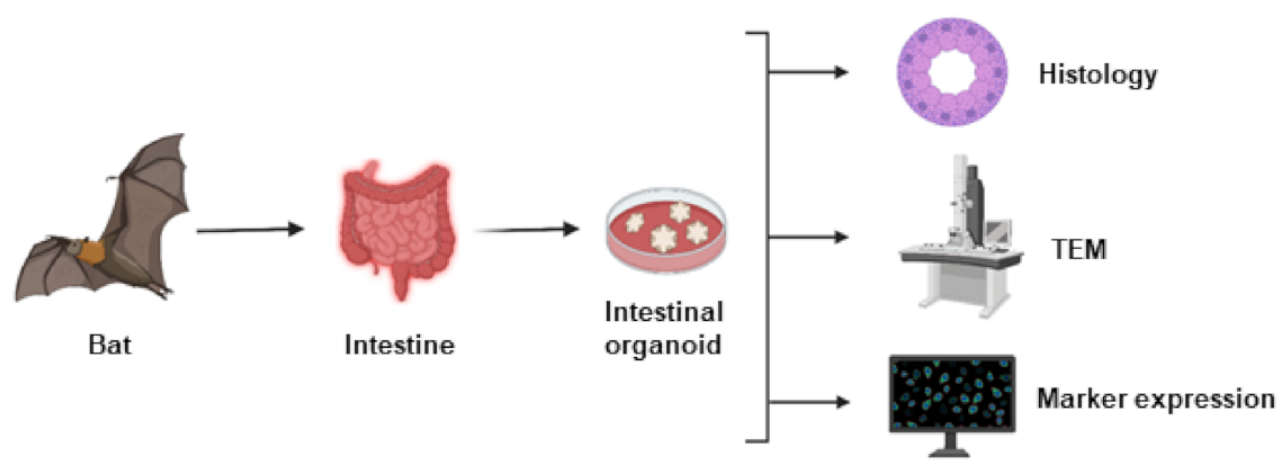

B

C

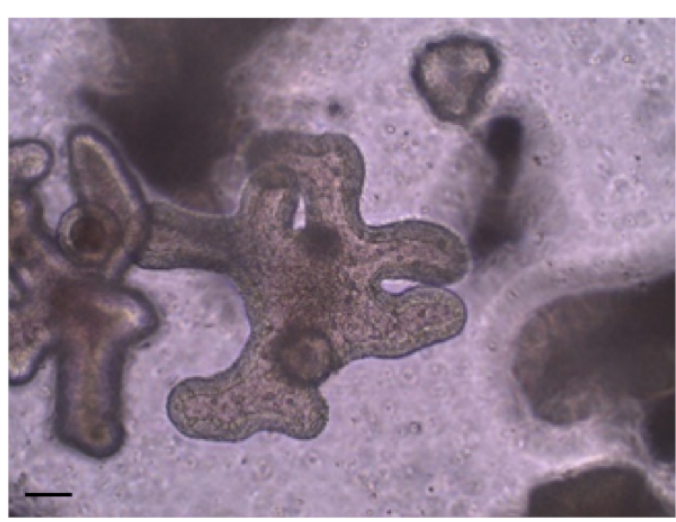

Intestinal organoid

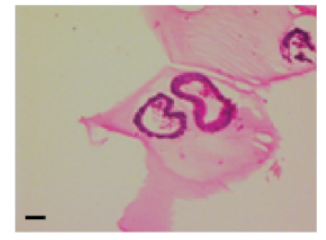

Intestinal tissue

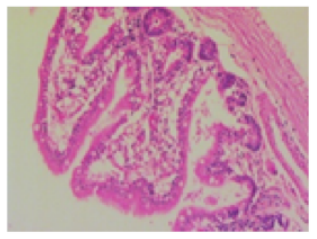

D

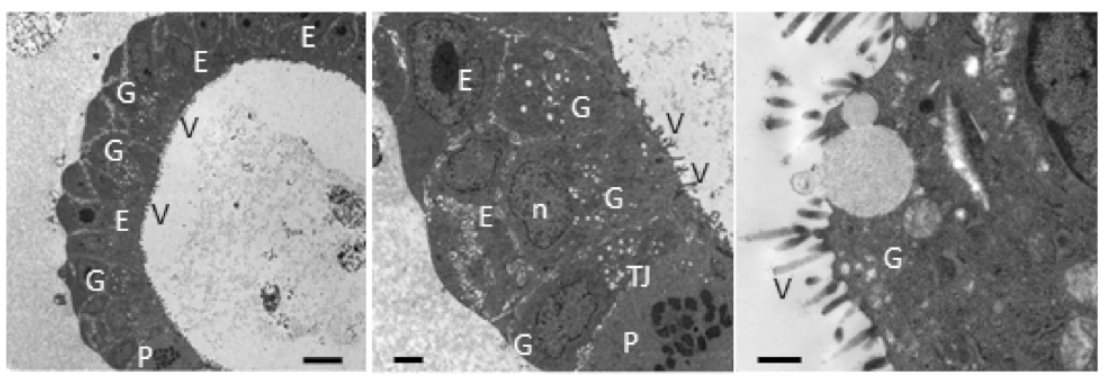

Figure 1. Generation of primary rousette bat intestinal organoids. Experimental schema of establishment and analysis of Rousette bat intestinal organoids (A). Bat intestinal tissues were isolated and cultured for generating their organoids. Then, each tissue-derived organoid was used for the analysis of histology, microstructure by transmission electron microscopy (TEM), and marker expression. Representative phase-contrast images of the organoids (passage 8 at day 10). Scale bar: $200 \mu \mathrm{m}$ (B). Hematoxylin and eosin-stained bat organoids and original tissues. Scale bar: $100 \mu \mathrm{m}$ (C). TEM photomicrographs of organoids (D). The absorptive epithelial cells (E), nucleus (n), microvilli (V), tight junction (TJ), goblet cells (G), and Paneth cells (P) are shown. Scale bar: $8 \mu \mathrm{m}, 2 \mu \mathrm{m}, 600 \mathrm{~nm}$ from left to right panel, respectively.

\subsection{Characterization of Bat Organoid}

To characterize rousette bat intestinal organoids, the expression of several specific cellular markers of intestinal tissues was evaluated by immunofluorescence staining. Ecadherin, an epithelial cell marker, CK20, a mature enterocyte marker, and MUC2, an 
intestinal goblet cell marker, were detected in the organoids and bat intestinal tissues, and both E-cadherin and CK20 were positive only in the outer layer of the organoids, whereas LGR5, an intestinal stem cell marker, was more abundant in the organoids than in the original tissues (Figure 2). These data indicate that the organoids recapitulated the cellular components of intestinal tissues with high stemness.
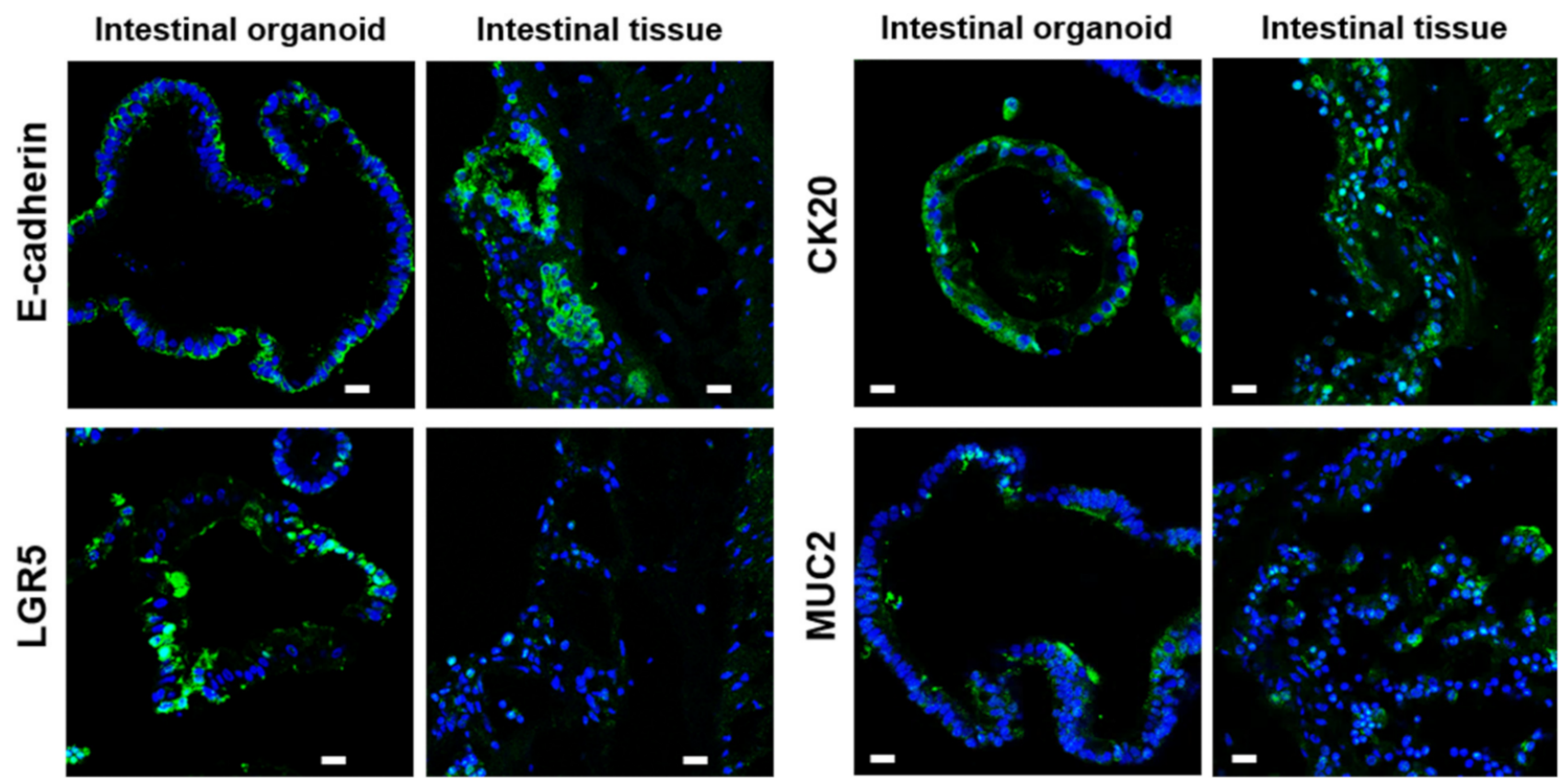

Figure 2. Characterization of the cellular components of the intestinal organoids from rousette bats. Expression of an epithelial cell marker, E-cadherin, an intestinal stem cell marker, LGR5, a mature enterocyte marker, CK20, and an intestinal goblet cell marker, MUC2. Scale bar: $50 \mu \mathrm{m}$.

\subsection{Evaluation of Appropriate Growth and Maintenance Media for Rousette Bat Organoids}

For long-term culture, the organoids were cultured with several supplements: Wnt 3a, Noggin, R-spondin (WNR), EGF, FGF2, FGF7, FGF10, IGF, or TGF- $\alpha$. The same number of organoid cells was seeded, and the growth and proliferation rates of the organoids were evaluated. There were significant differences in the effects of supplements on the growth and proliferation rates of rousette bat organoids (Figure 3). On day 7, the growth and proliferation rates were significantly higher when using the base media (Cont) with WNR, TGF- $\alpha$, or EGF (Figure 3B,C). However, FGF2, FGF7, FGF10, and IGF had no significant effects compared to the control. Based on these results, we identified that WNR, EGF, and TGF- $\alpha$ are essential for the culture of rousette bat intestinal organoids. The organoids maintained active proliferation for 10 months. We also confirmed that long-term cryopreserved rousette bat intestinal organoids grew normally, and subsequent analyses were performed based on these culture conditions (basal medium plus L-WNR condition medium (Wnt, Noggin, and R-spondin), human epidermal growth factor (EGF, $50 \mathrm{ng} / \mathrm{mL}$ ), and transforming growth factor-alpha (TGF- $\alpha, 20 \mathrm{ng} / \mathrm{mL}$ ). 
A

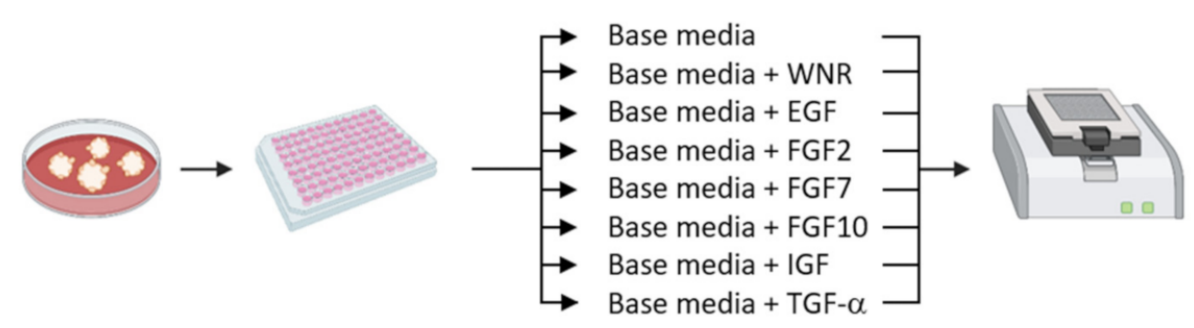

B

Cont

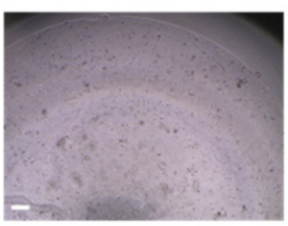

FGF7

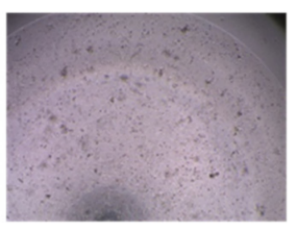

WNR

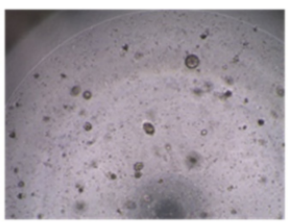

FGF10

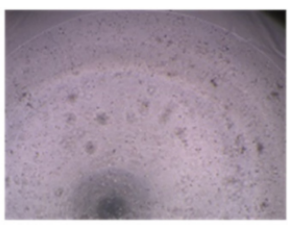

EGF

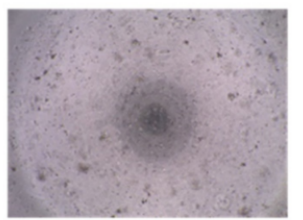

IGF1

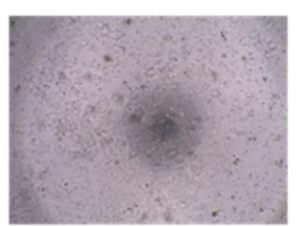

FGF2

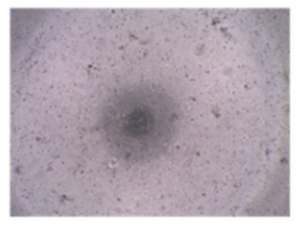

TGF- $\alpha$

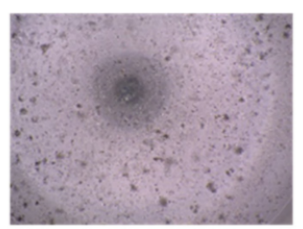

C

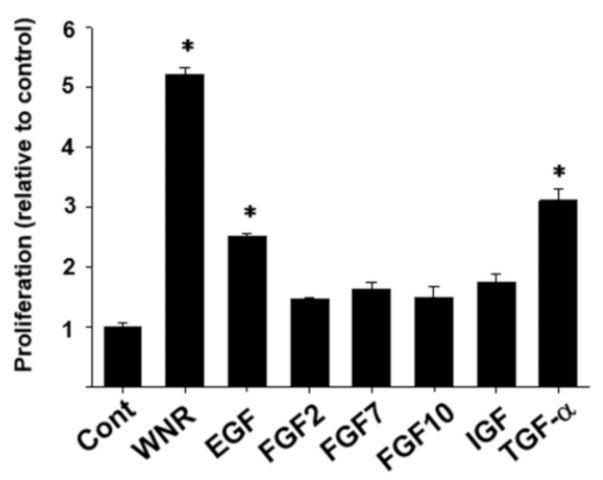

Figure 3. Identification of suitable culture supplements for intestinal organoids from the rousette bat. Experimental schema of identifying suitable media components of rousette bat organoids (A). Phase-contrast images of the growth of rousette bat intestinal organoids cultured in base medium alone (Cont) or with different culture supplements. WNR indicates Wnt 3a, Noggin, and R-spondin. Scale bar: $500 \mu \mathrm{m}(\mathbf{B})$. Cell proliferation ratio of organoids in each culture media (C). The results were shown as a fold increase relative to control and expressed as mean \pm S.E.M. ${ }^{*} p<0.05$ vs. control.

\subsection{Susceptibility of the Organoids to SARS-CoV-2 and PRV}

It has been confirmed that SARS-CoV-2 uses the ACE2 receptor for cell entry [4] with the aid of TMPRSS2 [31]. We analyzed the expression of ACE2 and TMPRSS2 in bat intestinal organoids. ACE2 was clearly expressed on the apical surface or basal membrane of organoids and in the intestinal tissues (Figure 4). TMPRSS2 was expressed not only at the basal surface but also at several sites in organoids and their original tissues (Figure 4). The amplification of SARS-CoV-2 could not be observed in either Matrigel or culture media of intestinal organoids from $R$. leschenalutii. The rousette bat intestinal organoid did not show $\mathrm{CPE}$, and the virus genome was not detected at any time point (data not shown). In contrast, PRV was amplified in the rousette bat intestinal organoids (Figure 5). The levels of PRV genome in Matrigel increased to $3.2 \times 10^{9}$ copies $/ \mathrm{mL}$ at $24 \mathrm{hpi}$ and 
peaked at $1.4 \times 10^{10}$ copies $/ \mathrm{mL}$ at $48 \mathrm{hpi}$. In the culture media, the levels of the PRV genome were lower than those in Matrigel. At $24 \mathrm{hpi}$, the levels of the PRV genome were $1.4 \times 10^{6}$ copies $/ \mathrm{mL}$ and peaked at $1.1 \times 10^{9}$ copies $/ \mathrm{mL}$ at $72 \mathrm{hpi}$. CPE was identified at $24 \mathrm{hpi}$ (Figure 5). In mock infection, the three-dimensional structure for the intestinal organoids at 24 and 48 hpi was maintained. On the other hand, PRV-infected organoids showed a progressive cytopathic effect indicated by a disruption of structural integrity as loss of membrane and cell-cell attachments, appearance of multinucleated giant cell-like structure, and apoptosis-like changes (Figure 6). These changes indicate that the rousette bat intestinal organoids are susceptible to PRV but not to SARS-CoV-2.
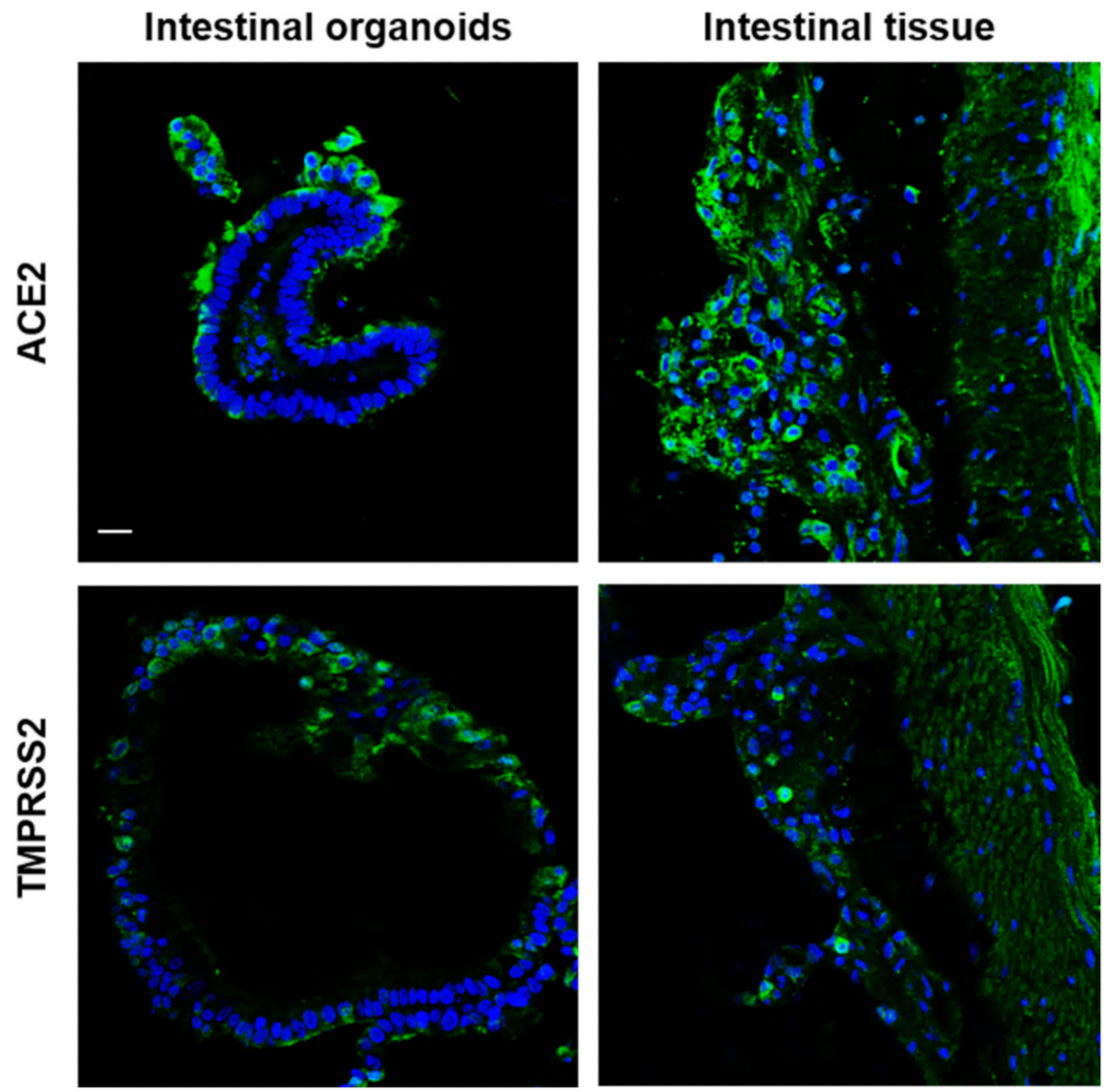

Figure 4. Localization of ACE2 and TMPRSS2 proteins in the rousette bat organoids and the bat intestine. ACE2 (green) or TMPRSS2 (green) proteins were stained using antibodies against each human homologue and merged with DAPI (blue). Scale bar: $50 \mu \mathrm{m}$. 


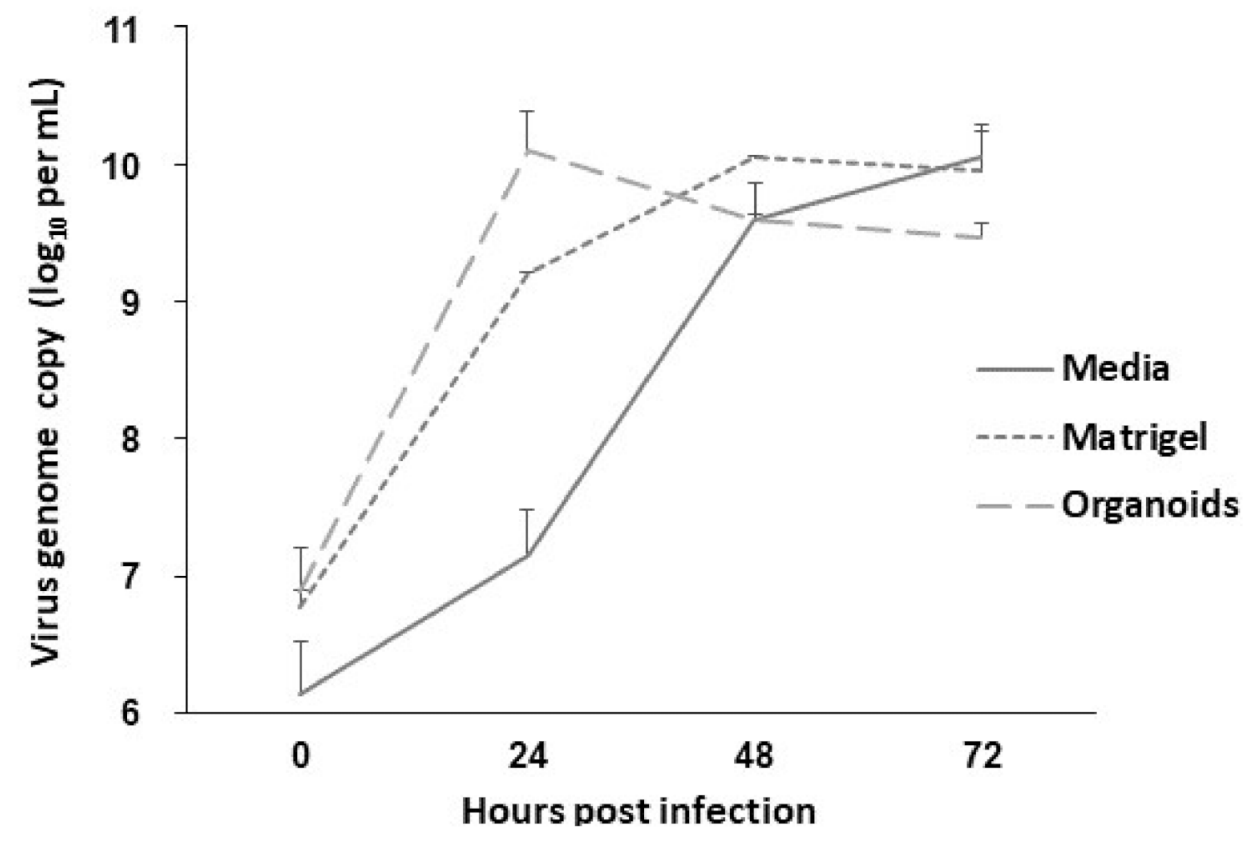

Figure 5. Growth curve of PRV in Matrigel, culture media, and organoids over $72 \mathrm{~h}$. Rousette bat intestinal organoids were infected at MOI $=0.1$. The amount of PRV genome was quantified by RT-PCR assay. The infection experiment was performed in technical triplicate, and the quantification of the virus genome was performed in duplicate. The values were shown as the mean \pm S.E.M $(n=3)$.

\section{Mock}

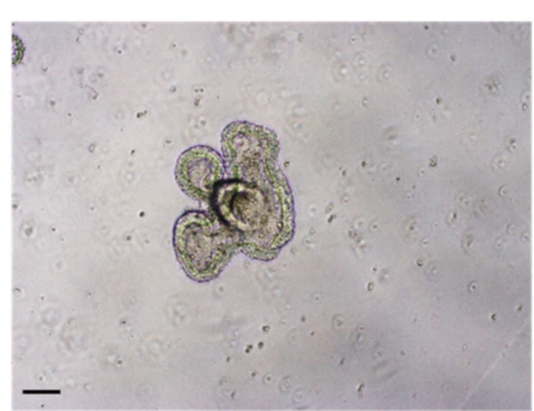

24 hpi

48 hpi

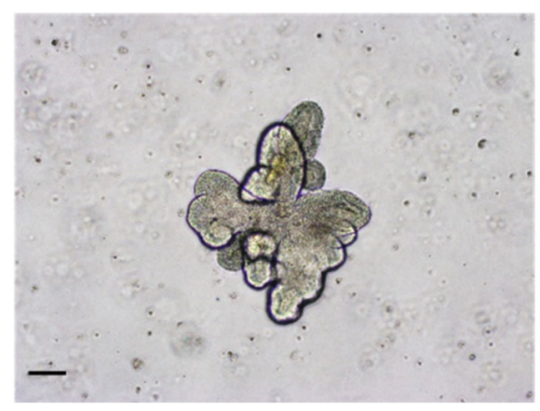

PRV
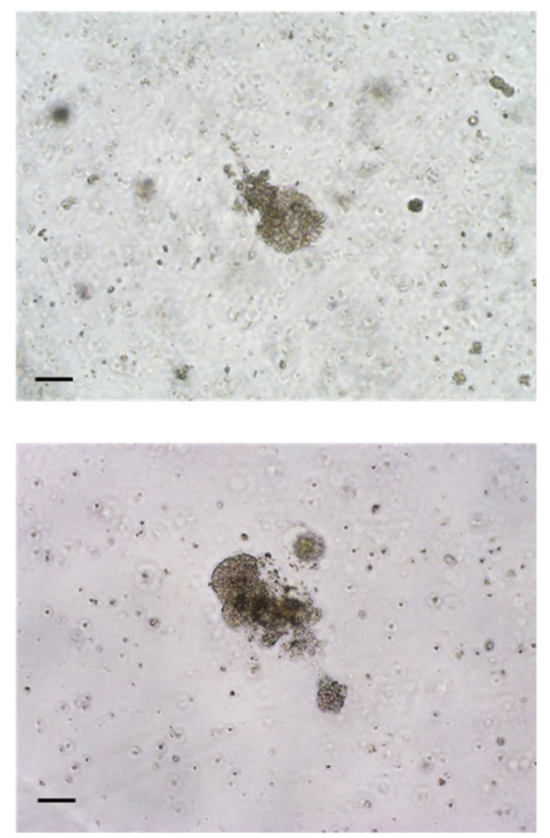

Figure 6. Representative phase-contrast images of mock-infected (Mock) and PRV-infected organoids (PRV). The upper and lower were 24 and 48 hpi, respectively. Scale bar: $200 \mu \mathrm{m}$.

\section{Discussion}

The bat (order Chiroptera) is a natural reservoir of several emerging and re-emerging viruses that induce severe infectious diseases, including Ebola virus, Marburg virus, Nipah virus, Hendra virus, SARS-CoV, MERS-CoV, and SARS-CoV-2. To investigate these bat-derived infectious diseases, in vivo bat assays are an important experimental tool. 
However, bats are wild animals, not experimental animals, and it is very difficult to conduct reproducible animal experiments. In this study, we successfully developed intestinal organoids from a Megachiroptera, Rousettus leschenaultia, and established a long-term stable culture method for the first time. The rousette bat intestinal organoids showed the same cellular composition as intestinal tissues from morphological and immunohistochemical characterizing analyses, as demonstrated previously in bats [30] and humans [32].

Additionally, we identified the appropriate culture supplements for maintaining the long-term culture of rousette bat intestinal organoids without ceasing active proliferation. However, for intestinal organoids from the horseshoe bat Rhinolophus sinicus, a long-term stable culture could not be achieved [30]. In rousette bat intestinal organoids, the base medium with WNR, TGF- $\alpha$, and EGF showed promising effects on growth and proliferation (Figure 3). In intestinal organoid cultures from other animals, including humans and mice, the combination of EGF and WNR is necessary to indefinitely proliferate and expand cells and recapitulate the differentiated cell diversity of the original tissue [33] because these supplements are necessary for the survival of LGR5 ${ }^{+}$intestinal stem cells [34,35]. Although IGF exists at a high level in the human bloodstream [36] and has been demonstrated to stimulate crypt expansion in mice $[37,38]$, it did not promote the proliferation of the organoid. In the same context, FGF2, which is expressed in the mesenchymal cells adjoining the intestinal crypts of mice and is upregulated following tissue injury to promote regeneration [39], had no significant effects on organoid expansion. FGF7 was identified as a differentiation factor in the developing lung [40] and controls the branching of the airway epithelium by promoting epithelial cell expansion and proliferation [41,42]. Lung organotypic culture studies revealed that the addition of FGF7 to the culture medium can induce AT2-like epithelial cell differentiation, even in the absence of any mesenchyme or serum $[42,43]$. TGF- $\alpha$, a ligand for the EGF receptor, is expressed in many types of cells, including intestinal and lung cells, and shows a promising effect on their growth and proliferation for maintaining their long-term culture. TGF- $\alpha$ binds to the EGF receptor and activates tyrosine kinase signaling, which results in the proliferation and differentiation of gastrointestinal and lung epithelium, especially following injury [44-46]. In addition, CD24 ${ }^{+}$Paneth cells express EGF, TGF- $\alpha$, and Wnt3a, which are necessary for stem cell maintenance in the culture of intestinal crypts [47]. In the lung, EGF and TGF- $\alpha$ mediate morphogenesis and repair [44]. EGF has also been detected in AT2 cells and bronchiolar, ciliated, and non-ciliated cells [48]. EGF and TGF- $\alpha$ have been reported to alter branching morphogenesis and differentiation of the developing lungs of mice [49]. These data indicate the importance of these supplements in the culture medium of bat rousette intestinal organoids.

The rousette bat intestinal organoid is a useful tool for the evaluation of virus susceptibility in vitro. In this study, we showed that SARS-CoV-2 was not amplified in the rousette bat intestinal organoids, but PRV increased $24 \mathrm{~h}$ post-inoculation. The sequence of ACE2 is conserved between R. aegyptiacus and R. leschenaultii, and ACE2 of R. aegyptiacus has the ability to support SARS-CoV-2 entry [50]. In binding assay between ACE2 orthologs of animals including $R$. leschenaultia and the receptor-binding domain for SARS-CoV-2 and RaTG13, closer species of SARS-CoV-2 detected from Rhinolophus bats, the affinity of ACE2 to RBD of each virus species was different among species in bats, and ACE2 of $R$. leschenaultia showed a low affinity [51]. Experimentally, intranasal inoculation of SARS-CoV-2 with R. aegyptiacus resulted in a transient infection of the respiratory tract [10]. However, WINV1-CoV and SARS-like CoV isolated from Rhinolophus sinicus did not cause a robust infection in $R$. aegyptiacus, and the cell line from the intestine of $R$. leschenaultii did not support SARS-CoV-2 infection [29,50]. Furthermore, the susceptibility of rousette bats to SARS-CoV-2 is controversial. In this study, the bat intestinal organoids did not show susceptibility to SARS-CoV-2, although ACE2 and TMPRSS2 were expressed. The intestinal organoids from Rhinorophus sinicus, one of the Rhinolophus spp. thought to be a natural reservoir of SARS-CoV and SARS-CoV-2, were susceptible to SARS-CoV-2 infection and showed viral replication within $72 \mathrm{~h}$ post-infection with $\mathrm{MOI}=0.1$ [30]. PRV was 
also isolated from patients with respiratory tract infections and has been isolated from bats, including R. leschenaultii $[15,18,52,53]$, and the PRV Samal-24 strain was isolated from E. spelaea in the Philippines in 2013 [20]. PRV could be propagated in the rousette bat intestinal organoid and showed CPE at $48 \mathrm{~h}$ post-inoculation in this study. These results indicate that rousette bat intestinal organoids are useful tools to evaluate virus susceptibility and tolerance mechanisms of viruses, including Ebola and Marburg viruses.

\section{Materials and Methods}

\subsection{Preparation of Rousette Bat Tissues}

Intestinal tissue was collected from five rousettes of Leschenault (Rousettus leschenaultii), which were kindly supplied by Ueno Zoo (Tokyo, Japan) and Chiba Zoological Park (Chiba, Japan). These bats were confirmed to have died of natural causes at the zoo, and intestinal tissues were collected. The collected tissues were placed in a preservation culture medium and transported to the laboratory under refrigeration conditions.

\subsection{Establishment of Bat Intestinal Organoid}

The collected intestinal tissues were washed three times with cold phosphate buffer saline (PBS), chopped into fine pieces, and transferred into tubes containing advanced Dulbecco's modified Eagle's medium (DMEM) with $0.125 \mathrm{mg} / \mathrm{mL}$ Liberase TH for digestion and isolation of intestinal crypt cells. The tubes were then incubated at $37^{\circ} \mathrm{C}$ in a shaking incubator for $30 \mathrm{~min}$ and pipetted every $15 \mathrm{~min}$. The resultant cell suspension was then passed into a $70 \mu \mathrm{m}$ nylon net cell strainer and spun down at $600 \times \mathrm{g}$ for $5 \mathrm{~min}$ at $4{ }^{\circ} \mathrm{C}$. The cell pellets were then washed three times with PBS, suspended in Matrigel on ice, and dispersed in a 24-well plate $(40 \mu \mathrm{L} /$ well). After the Matrigel was polymerized to form a droplet in a $\mathrm{CO}_{2}$ incubator at $37^{\circ} \mathrm{C}$ for $30 \mathrm{~min}, 500 \mu \mathrm{L}$ of stem cell-stimulating medium was added to each well. The medium was changed 2-3 times weekly. Organoids were passaged every 7-14 days using $5 \mathrm{mM}$ EDTA-PBS solution at 1:2-4 split as described previously [54]. Photomicrographs of the organoids were acquired using an Olympus CKX-31 inverted microscope (Olympus, Tokyo, Japan).

\subsection{Investigation of Suitable Supplementation for Organoid Culture}

To investigate the suitable culture conditions for rousette bat organoids, various supplements were individually applied, and the growth, proliferation rate, and maintenance of the organoids were evaluated. The organoids were treated with TrypLE (Life Technologies Co., Grand Island, NY, USA) for 5 min and strained using a $70 \mu \mathrm{m}$ cell strainer (Falcon, Cary, NC, USA). Thereafter, $1 \times 10^{3}$ organoid cells were seeded into $10 \mu \mathrm{L}$ Matrigel in 96-well culture plates and incubated at $5 \% \mathrm{CO}_{2}$ at $37{ }^{\circ} \mathrm{C}$ for $30 \mathrm{~min}$. In the culture of intestinal organoids from humans, mice, and other animals, human epidermal growth factor (EGF) and WNR (Wnt, Noggin, and R-spondin) were shown to be necessary for the proliferation, expansion of the cells, and maintaining the cellular diversity of the original tissues [33-35]. Thus, we tried the effects of several culture supplements on the growth and proliferation of organoids. After polymerization of the Matrigel, the organoid cells were cultured under conditions in which one of the following supplements was added to the basal medium and compared to basal medium only: L-WNR condition medium, EGF (50 ng/mL, PeproTech, Inc., East Windsor, NJ, USA), fibroblast growth factor-2 (FGF2, 20 ng/mL, PeproTech, Inc.), FGF7 (5 ng/mL, PeproTech, Inc.), FGF10 (20 ng/mL, PeproTech, Inc.), insulin-like growth factor (IGF, $10 \mathrm{ng} / \mathrm{mL}$, PeproTech, Inc.), and transforming growth factor-alpha (TGF- $\alpha)(20 \mathrm{ng} / \mathrm{mL}$, PeproTech, Inc.). Quantification of the effects on growth and proliferation of organoids was performed on day seven after culture using the PrestoBlue assay kit (Thermo Fisher Scientific, Eugene, OR, USA) and a microplate reader (TECAN, Seestrasse, Switzerland). 


\subsection{Histopathological and Immunohistochemical Examination}

Hematoxylin and eosin staining was conducted for histopathological analysis, as described previously $[25,55,56]$. Concisely, after fixing the intestinal tissue and organoids with a $4 \%$ paraformaldehyde (PFA) solution (Fujifilm, Osaka, Japan) at room temperature (RT) for $24 \mathrm{~h}$ and $2-3 \mathrm{~h}$, respectively, these samples were embedded in paraffin and sliced into $5 \mu \mathrm{m}$-thick sections and mounted onto MS-coated glass slides. Following deparaffinization, the sections were stained with hematoxylin and eosin using a standard protocol, and the photomicrographs were captured using an Olympus BX-52 inverted microscope. Immunofluorescence staining of intestinal tissues and organoids was performed as previously described $[54,55]$. The tissues and organoids were fixed in $4 \%$ PFA for $1 \mathrm{~h}$ at RT and dehydrated with a $30 \%$ sucrose solution at $4{ }^{\circ} \mathrm{C}$ overnight. Subsequently, they were embedded in OCT compound (Sakura Finetek Inc., Torrance, CA, USA) and kept at $-80^{\circ} \mathrm{C}$ until slicing. The frozen sections were prepared and treated with $1.5 \%$ normal goat serum in PBS at RT for $1 \mathrm{~h}$. Sections were then incubated with primary antibodies (E-cadherin; 1:100, cytokeratin 20 (CK20); 1:200, mucin 5AC (MUC5AC); 1:200, transmembrane protease serine 2 (TMPRSS2); 1:200, CK5; 1:200; angiotensin-converting enzyme II (ACE2); 1:200, mucin 2 (MUC2); 1:200, leucine-rich repeat-containing G-protein coupled receptor 5 (LGR5); 1:200, secretoglobin family 1A member 1 (SCGB1A1); 1:200, and surfactant-associated protein $\mathrm{C}$ (SFTPC) 1:200) and kept at $4{ }^{\circ} \mathrm{C}$ overnight. The sections were then washed three times with PBS and incubated with the secondary antibodies and Hoechst stain for $1 \mathrm{~h}$ in the dark at RT. After washing, a small drop of Fluoromount solution (Diagnostic Biosystems, Pleasanton, CA, USA) was added per section and covered by a coverslip. The sections were then allowed to dry for $2 \mathrm{~h}$ in the dark at RT. Images were captured using a confocal microscope (LSM 800; ZEISS, Copenhagen, Germany).

The antibodies used in this study were as follows: E-cadherin (R\&D System, Minneapolis, MN, USA); CK20; MUC5AC; TMPRSS2; SCGB1A1 (Bioss, Woburn, MA, USA); CK5, ACE2; MUC2 (GeneTex, Inc., Irvine, CA, USA); LGR5; (Abgent California, CA, USA); SFTPC (Affinity Biosciences LTD, OH, USA). Fluorescent secondary antibodies were as follows: Alexa Fluor 488 goat anti-rabbit IgG and Alexa Fluor 488 goat anti-mouse IgG (Thermo Fisher Scientific Inc.).

\subsection{Transmission Electron Microscopy (TEM)}

After the organoids were fixed with $2.5 \%$ glutaraldehyde for $3 \mathrm{~h}$ at RT in $0.1 \%$ cacodylate (pH 7.4), they were washed once with $0.1 \mathrm{M}$ cacodylate ( $\mathrm{pH}$ 7.4), followed by incubation in $2 \%$ osmium tetroxide and $1.5 \% \mathrm{~K}_{4} \mathrm{Fe}(\mathrm{CN})_{6}$ in $0.1 \mathrm{M}$ sodium cacodylate ( $\mathrm{pH} 7.4$ ) for $2 \mathrm{~h}$ at $4{ }^{\circ} \mathrm{C}$. After rinsing with distilled water, the organoids were dehydrated in a graded ethanol series $(50 \%, 70 \%, 80 \%, 90 \%, 95 \%$, and 99.5 up to $100 \%)$ and embedded in Epon. Ultrathin sections of 70-110 nm were cut with a diamond knife on a Leica UC7 ultramicrotome and transferred onto 50-mesh copper grids covered with a form bar and carbon film. The sections were post-stained with uranyl acetate for $15 \mathrm{~min}$ at RT and lead citrate. Sections were imaged using a transmission electron microscope $(\mathrm{H}-7500$, Hitachi, Tokyo, Japan) using a TEM digital camera (NanoSprint500, Hitachi).

\subsection{Sensitivity of Organoid to SARS-CoV-2 and Pteropine Orthoreovirus}

The Pteropine orthoreovirus Samal-24 strain (PRV) was kindly provided by M. Shimojima, Department of Virology I, NIID, Japan, and SARS-CoV-2 was isolated from swab samples at NIID, Japan. To investigate the replication kinetics of these viruses in the organoid, the organoid was infected with the virus at an MOI of 0.1 [30]. To prepare the organoids for virus infection, $500 \mu \mathrm{L}$ of ice-cold $5 \mathrm{mM}$ EDTA-PBS was added per well of a 24-well plate and incubated on ice for $90 \mathrm{~min}$. Thereafter, organoids were collected, trypsinized, and passed through a $70 \mu \mathrm{m}$ cell strainer. An equal number of cells was seeded per well. After enough growth and typical morphology, the Matrigels with organoids were sheared gently and organoids were collected. After centrifugation, equal volumes of organoid pellets were confirmed using a weight/volume-based approach, and MOI 
0.1 was then adjusted. Subsequently, organoids were incubated in a medium containing MOI 0.1 of SARS-CoV-2 or PRV at $37^{\circ} \mathrm{C}$ for $1 \mathrm{~h}$. After incubation, the organoids were washed once with PBS, resuspended in Matrigel on ice, and dispersed in a 24-well plate (40 $\mu \mathrm{L} /$ well). After the Matrigel was polymerized to form a droplet in a $\mathrm{CO}_{2}$ incubator at $37^{\circ} \mathrm{C}$ for $30 \mathrm{~min}, 500 \mu \mathrm{L}$ of medium was added to each well. At 2, 24, 48, and $72 \mathrm{~h}$ post-inoculation (hpi), media was collected, the Matrigel was washed once by ice-cold PBS, and $350 \mu \mathrm{L}$ of $5 \mathrm{mM}$ EDTA-PBS was added to each well and incubated on ice for $90 \mathrm{~min}$. The dissociated Matrigel was centrifuged, and the supernatant solution was collected and used for RNA extraction with a High Pure Viral RNA kit (Roche) for RNA extraction. Extracted RNAs were used to detect each viral genome by RT-qPCR, as described previously $[57,58]$. Matrigel was also collected to evaluate the viral genome level using a real-time PCR assay. Infection experiments and genome detection were performed in triplicate and duplicate, respectively.

\subsection{Statistical Analysis}

Data are expressed as the mean \pm SEM. Statistical significance was evaluated using one-way analysis of variance (ANOVA) followed by Bonferroni's test. Statistical significance was set at $p<0.05$.

\section{Conclusions}

We have improved the culture method of rousette bat intestinal organoids for longterm use, and the intestinal organoids were able to reproduce the multicellular structure of the intestinal epithelium. We expect that the long-term storage of rousette bat intestinal organoids produced in this study will provide a new experimental platform for the isolation and study of other bat pathogens with high zoonotic potential.

Author Contributions: Conceptualization, M.E., T.U. and T.O.; methodology, M.E., Y.K., N.S., K.H., A.A. and M.K. (Masahiro Kaneda); software, M.E. and T.U.; validation, T.Y., M.S. (Makoto Shibutani), T.U. and T.O.; formal analysis, M.E., Y.K., N.S. and T.U.; investigation, M.E., Y.K., M.K. (Mio Kobayashi) and K.S.; resources, M.K. (Masahiro Kaneda), T.Y., M.S., C.-K.L. and M.S. (Masayuki Saijo); data curation, M.E., T.U. and T.O.; writing-original draft preparation, M.E. and T.O.; writingreview and editing, T.U., H.Y. and K.S.; visualization, M.E., Y.K. and T.M.; supervision, T.U., K.S. and T.O.; funding acquisition, T.U. and T.O. All authors have read and agreed to the published version of the manuscript.

Funding: This research was funded by a Grant-in-Aid for Scientific Research from the Japan Society for the Promotion of Science (JSPS) Grant Number is $20 \mathrm{H} 03145$.

Institutional Review Board Statement: Not applicable.

Informed Consent Statement: Not applicable.

Data Availability Statement: The detailed data of the current study are available from the corresponding authors on reasonable requests.

Acknowledgments: We would like to acknowledge the Exhibits and Husbandry Department, Ueno Zoological Gardens, and Tokyo Zoological Park Society for providing the bat intestines.

Conflicts of Interest: The authors declare no conflict of interest. The funders had no role in the design of the study; in the collection, analyses, and interpretation of data; in the writing of the manuscript, and in the decision to publish the results.

\section{References}

1. Munster, V.J.; Adney, D.R.; van Doremalen, N.; Brown, V.R.; Miazgowicz, K.L.; Milne-Price, S.; Bushmaker, T.; Rosenke, R.; Scott, D.; Hawkinson, A.; et al. Replication and shedding of MERS-CoV in Jamaican fruit bats (Artibeus jamaicensis). Sci. Rep. 2016, 6, 21878. [CrossRef]

2. Drosten, C.; Gunther, S.; Preiser, W.; van der Werf, S.; Brodt, H.R.; Becker, S.; Rabenau, H.; Panning, M.; Kolesnikova, L.; Fouchier, R.A.; et al. Identification of a novel coronavirus in patients with severe acute respiratory syndrome. N. Engl. J. Med. 2003, 348, 1967-1976. [CrossRef] [PubMed] 
3. Wang, L.F.; Anderson, D.E. Viruses in bats and potential spillover to animals and humans. Curr. Opin. Virol. $2019,34,79-89$. [CrossRef] [PubMed]

4. Zhou, P.; Yang, X.L.; Wang, X.G.; Hu, B.; Zhang, L.; Zhang, W.; Si, H.R.; Zhu, Y.; Li, B.; Huang, C.L.; et al. A pneumonia outbreak associated with a new coronavirus of probable bat origin. Nature 2020, 579, 270-273. [CrossRef] [PubMed]

5. Coltart, C.E.; Lindsey, B.; Ghinai, I.; Johnson, A.M.; Heymann, D.L. The Ebola outbreak, 2013-2016: Old lessons for new epidemics. Philos. Trans. R. Soc. B. Biol. Sci. 2017, 372, 20160297. [CrossRef]

6. Pigott, D.M.; Golding, N.; Mylne, A.; Huang, Z.; Weiss, D.J.; Brady, O.J.; Kraemer, M.U.; Hay, S.I. Mapping the zoonotic niche of Marburg virus disease in Africa. Trans. R. Soc. Trop. Med. Hyg. 2015, 109, 366-378. [CrossRef] [PubMed]

7. Muzeniek, T.; Perera, T.; Siriwardana, S.; Bas, D.; Kaplan, F.; Öruc, M.; Becker-Ziaja, B.; Schwarz, F.; Premawansa, G.; Premawansa, S.; et al. Detection of Alpha- and Betacoronaviruses in Miniopterus fuliginosus and Rousettus leschenaultii, two species of Sri Lankan Bats. Vaccines 2021, 9, 650. [CrossRef] [PubMed]

8. Lacroix, A.; Vidal, N.; Keita, A.K.; Thaurignac, G.; Esteban, A.; De Nys, H.; Diallo, R.; Toure, A.; Goumou, S.; Soumah, A.K.; et al. Wide Diversity of Coronaviruses in Frugivorous and Insectivorous Bat Species: A Pilot Study in Guinea, West Africa. Viruses 2020, 12, 855. [CrossRef] [PubMed]

9. Yadav, P.D.; Shete-Aich, A.; Nyayanit, D.A.; Pardeshi, P.; Majumdar, T.; Balasubramanian, R.; Ullas, P.T.; Mohandas, S.; Dighe, H.; Sawant, P.; et al. Detection of coronaviruses in Pteropus \& Rousettus species of bats from different States of India. Indian J. Med. Res. 2020, 151, 226-235.

10. Schlottau, K.; Rissmann, M.; Graaf, A.; Schön, J.; Sehl, J.; Wylezich, C.; Höper, D.; Mettenleiter, T.C.; Balkema-Buschmann, A.; Harder, T.; et al. SARS-CoV-2 in fruit bats, ferrets, pigs, and chickens: An experimental transmission study. Lancet Microbe 2020, 1, e218-e225. [CrossRef]

11. Pourrut, X.; Souris, M.; Towner, J.S.; Rollin, P.E.; Nichol, S.T.; Gonzalez, J.P.; Leroy, E. Large serological survey showing cocirculation of Ebola and Marburg viruses in Gabonese bat populations, and a high seroprevalence of both viruses in Rousettus aegyptiacus. BMC Infect. Dis. 2009, 9, 159. [CrossRef] [PubMed]

12. Taniguchi, S.; Watanabe, S.; Masangkay, J.S.; Omatsu, T.; Ikegami, T.; Alviola, P.; Ueda, N.; Iha, K.; Fujii, H.; Ishii, Y.; et al. Reston Ebolavirus antibodies in bats, the Philippines. Emerg. Infect. Dis. 2011, 17, 1559-1560. [CrossRef] [PubMed]

13. Yuan, J.; Zhang, Y.; Li, J.; Zhang, Y.; Wang, L.F.; Shi, Z. Serological evidence of ebolavirus infection in bats, China. Virol. J. 2012, 9 , 236. [CrossRef]

14. Paweska, J.T.; Jansen van Vuren, P.; Masumu, J.; Leman, P.A.; Grobbelaar, A.A.; Birkhead, M.; Clift, S.; Swanepoel, R.; Kemp, A. Virological and serological findings in Rousettus aegyptiacus experimentally inoculated with vero cells-adapted hogan strain of Marburg virus. PLoS ONE 2012, 7, e45479. [CrossRef] [PubMed]

15. Gard, G.P.; Marshall, I.D. Nelson Bay virus. A novel reovirus. Archiv fur die gesamte Virusforschung 1973, 43, 34-42. [CrossRef]

16. Chua, K.B.; Crameri, G.; Hyatt, A.; Yu, M.; Tompang, M.R.; Rosli, J.; McEachern, J.; Crameri, S.; Kumarasamy, V.; Eaton, B.T.; et al. A previously unknown reovirus of bat origin is associated with an acute respiratory disease in humans. Proc. Natl. Acad. Sci. USA 2007, 104, 11424-11429. [CrossRef]

17. Voon, K.; Chua, K.B.; Yu, M.; Crameri, G.; Barr, J.A.; Malik, Y.; Wang, L.F. Evolutionary relationship of the L- and M-class genome segments of bat-borne fusogenic orthoreoviruses in Malaysia and Australia. J. Gen. Virol. 2011, 92 Pt 12, 2930-2936. [CrossRef]

18. Hu, T.; Qiu, W.; He, B.; Zhang, Y.; Yu, J.; Liang, X.; Zhang, W.; Chen, G.; Zhang, Y.; Wang, Y.; et al. Characterization of a novel orthoreovirus isolated from fruit bat, China. BMC Microbiol. 2014, 14, 293. [CrossRef]

19. Singh, H.; Shimojima, M.; Ngoc, T.C.; Quoc Huy, N.V.; Chuong, T.X.; Le Van, A.; Saijo, M.; Yang, M.; Sugamata, M. Serological evidence of human infection with Pteropine orthoreovirus in Central Vietnam. J. Med. Virol. 2015, 87, 2145-2148. [CrossRef]

20. Taniguchi, S.; Maeda, K.; Horimoto, T.; Masangkay, J.S.; Puentespina, R., Jr.; Alvarez, J.; Eres, E.; Cosico, E.; Nagata, N.; Egawa, K.; et al. First isolation and characterization of pteropine orthoreoviruses in fruit bats in the Philippines. Arch. Virol. 2017, 162, 1529-1539. [CrossRef]

21. Middendorp, S.; Schneeberger, K.; Wiegerinck, C.L.; Mokry, M.; Akkerman, R.D.; van Wijngaarden, S.; Clevers, H.; Nieuwenhuis, E.E. Adult stem cells in the small intestine are intrinsically programmed with their location-specific function. Stem. Cells 2014, 32, 1083-1091. [CrossRef]

22. Kovbasnjuk, O.; Zachos, N.C.; In, J.; Foulke-Abel, J.; Ettayebi, K.; Hyser, J.M.; Broughman, J.R.; Zeng, X.L.; Middendorp, S.; de Jonge, H.R.; et al. Human enteroids: Preclinical models of non-inflammatory diarrhea. Stem. Cell Res. Ther. 2013, 4 (Suppl. 1), S3. [CrossRef] [PubMed]

23. Saxena, K.; Blutt, S.E.; Ettayebi, K.; Zeng, X.L.; Broughman, J.R.; Crawford, S.E.; Karandikar, U.C.; Sastri, N.P.; Conner, M.E.; Opekun, A.R.; et al. Human Intestinal Enteroids: A New Model To Study Human Rotavirus Infection, Host Restriction, and Pathophysiology. J. Virol. 2016, 90, 43-56. [CrossRef]

24. Abugomaa, A.; Elbadawy, M. Patient-derived organoid analysis of drug resistance in precision medicine: Is there a value? Expert Rev. Precis. Med. Drug Dev. 2020, 5, 1-5. [CrossRef]

25. Abugomaa, A.; Elbadawy, M.; Yamanaka, M.; Goto, Y.; Hayashi, K.; Mori, T.; Uchide, T.; Azakami, D.; Fukushima, R.; Yoshida, T.; et al. Establishment of 2.5D organoid culture model using 3D bladder cancer organoid culture. Sci. Rep. 2020, 10, 9393. [CrossRef] 
26. Elbadawy, M.; Sato, Y.; Mori, T.; Goto, Y.; Hayashi, K.; Yamanaka, M.; Azakami, D.; Uchide, T.; Fukushima, R.; Yoshida, T.; et al. Anti-tumor effect of trametinib in bladder cancer organoid and the underlying mechanism. Cancer Biol. Ther. 2021, $22,357-371$. [CrossRef] [PubMed]

27. Elbadawy, M.; Abugomaa, A.; Yamawaki, H.; Usui, T.; Sasaki, K. Development of prostate cancer organoid culture models in basic medicine and translational research. Cancers 2020, 12, 777. [CrossRef]

28. Elbadawy, M.; Usui, T.; Yamawaki, H.; Sasaki, K. Development of an experimental model for analyzing drug resistance in colorectal cancer. Cancers 2018, 10, 164. [CrossRef]

29. van Doremalen, N.; Schäfer, A.; Menachery, V.D.; Letko, M.; Bushmaker, T.; Fischer, R.J.; Figueroa, D.M.; Hanley, P.W.; Saturday, G.; Baric, R.S.; et al. SARS-Like Coronavirus WIV1-CoV Does Not Replicate in Egyptian Fruit Bats (Rousettus aegyptiacus). Viruses 2018, 10, 727. [CrossRef]

30. Zhou, J.; Li, C.; Liu, X.; Chiu, M.C.; Zhao, X.; Wang, D.; Wei, Y.; Lee, A.; Zhang, A.J.; Chu, H.; et al. Infection of bat and human intestinal organoids by SARS-CoV-2. Nat. Med. 2020, 26, 1077-1083. [CrossRef]

31. Hoffmann, M.; Kleine-Weber, H.; Schroeder, S.; Kruger, N.; Herrler, T.; Erichsen, S.; Schiergens, T.S.; Herrler, G.; Wu, N.H.; Nitsche, A.; et al. SARS-CoV-2 Cell Entry Depends on ACE2 and TMPRSS2 and Is Blocked by a Clinically Proven Protease Inhibitor. Cell 2020, 181, 271-280. [CrossRef] [PubMed]

32. Onozato, D.; Yamashita, M.; Nakanishi, A.; Akagawa, T.; Kida, Y.; Ogawa, I.; Hashita, T.; Iwao, T.; Matsunaga, T. Generation of Intestinal Organoids Suitable for Pharmacokinetic Studies from Human Induced Pluripotent Stem Cells. Drug Metab. Dispos. 2018, 46, 1572-1580. [CrossRef] [PubMed]

33. Sato, T.; Vries, R.G.; Snippert, H.J.; van de Wetering, M.; Barker, N.; Stange, D.E.; van Es, J.H.; Abo, A.; Kujala, P.; Peters, P.J.; et al. Single Lgr5 stem cells build crypt-villus structures in vitro without a mesenchymal niche. Nature 2009, 459, 262-265. [CrossRef] [PubMed]

34. Kuhnert, F.; Davis, C.R.; Wang, H.T.; Chu, P.; Lee, M.; Yuan, J.; Nusse, R.; Kuo, C.J. Essential requirement for Wnt signaling in proliferation of adult small intestine and colon revealed by adenoviral expression of Dickkopf-1. Proc. Natl. Acad. Sci. USA 2004, 101, 266-271. [CrossRef]

35. Bongers, G.; Muniz, L.R.; Pacer, M.E.; Iuga, A.C.; Thirunarayanan, N.; Slinger, E.; Smit, M.J.; Reddy, E.P.; Mayer, L.; Furtado, G.C.; et al. A role for the epidermal growth factor receptor signaling in development of intestinal serrated polyps in mice and humans. Gastroenterology 2012, 143, 730-740. [CrossRef] [PubMed]

36. Juul, A.; Bang, P.; Hertel, N.T.; Main, K.; Dalgaard, P.; Jorgensen, K.; Muller, J.; Hall, K.; Skakkebaek, N.E. Serum insulin-like growth factor-I in 1030 healthy children, adolescents, and adults: Relation to age, sex, stage of puberty, testicular size, and body mass index. J. Clin. Endocrinol. Metab. 1994, 78, 744-752.

37. Mah, A.T.; Van Landeghem, L.; Gavin, H.E.; Magness, S.T.; Lund, P.K. Impact of diet-induced obesity on intestinal stem cells: Hyperproliferation but impaired intrinsic function that requires insulin/IGF1. Endocrinology 2014, 155, 3302-3314. [CrossRef]

38. Van Landeghem, L.; Santoro, M.A.; Mah, A.T.; Krebs, A.E.; Dehmer, J.J.; McNaughton, K.K.; Helmrath, M.A.; Magness, S.T.; Lund, P.K. IGF1 stimulates crypt expansion via differential activation of 2 intestinal stem cell populations. FASEB J. 2015, 29, $2828-2842$. [CrossRef] [PubMed]

39. Song, X.; Dai, D.; He, X.; Zhu, S.; Yao, Y.; Gao, H.; Wang, J.; Qu, F.; Qiu, J.; Wang, H.; et al. Growth Factor FGF2 Cooperates with Interleukin-17 to Repair Intestinal Epithelial Damage. Immunity 2015, 43, 488-501. [CrossRef]

40. Akram, K.M.; Patel, N.; Spiteri, M.A.; Forsyth, N.R. Lung Regeneration: Endogenous and Exogenous Stem Cell Mediated Therapeutic Approaches. Int. J. Mol. Sci. 2016, 17, 128. [CrossRef] [PubMed]

41. Nogawa, H.; Ito, T. Branching morphogenesis of embryonic mouse lung epithelium in mesenchyme-free culture. Development 1995, 121, 1015-1022. [CrossRef]

42. Cardoso, W.V.; Itoh, A.; Nogawa, H.; Mason, I.; Brody, J.S. FGF-1 and FGF-7 induce distinct patterns of growth and differentiation in embryonic lung epithelium. Dev. Dyn. 1997, 208, 398-405. [CrossRef]

43. Shannon, J.M.; Gebb, S.A.; Nielsen, L.D. Induction of alveolar type II cell differentiation in embryonic tracheal epithelium in mesenchyme-free culture. Development 1999, 126, 1675-1688. [CrossRef]

44. Korfhagen, T.R.; Swantz, R.J.; Wert, S.E.; McCarty, J.M.; Kerlakian, C.B.; Glasser, S.W.; Whitsett, J.A. Respiratory epithelial cell expression of human transforming growth factor-alpha induces lung fibrosis in transgenic mice. J. Clin. Investig. 1994, 93, 1691-1699. [CrossRef] [PubMed]

45. Hoffmann, P.; Zeeh, J.M.; Lakshmanan, J.; Wu, V.S.; Procaccino, F.; Reinshagen, M.; McRoberts, J.A.; Eysselein, V.E. Increased expression of transforming growth factor alpha precursors in acute experimental colitis in rats. Gut 1997, 41, 195-202. [CrossRef] [PubMed]

46. Singh, B.; Coffey, R.J. From wavy hair to naked proteins: The role of transforming growth factor alpha in health and disease. Semin Cell Dev. Biol. 2014, 28, 12-21. [CrossRef]

47. Sato, T.; van Es, J.H.; Snippert, H.J.; Stange, D.E.; Vries, R.G.; van den Born, M.; Barker, N.; Shroyer, N.F.; van de Wetering, M.; Clevers, H. Paneth cells constitute the niche for Lgr5 stem cells in intestinal crypts. Nature 2011, 469, 415-418. [CrossRef]

48. Sannes, P.L.; Burch, K.K.; Khosla, J. Immunohistochemical localization of epidermal growth factor and acidic and basic fibroblast growth factors in postnatal developing and adult rat lungs. Am. J. Respir. Cell Mol. Biol. 1992, 7, 230-237. [CrossRef]

49. Warburton, D.; Seth, R.; Shum, L.; Horcher, P.G.; Hall, F.L.; Werb, Z.; Slavkin, H.C. Epigenetic role of epidermal growth factor expression and signalling in embryonic mouse lung morphogenesis. Dev. Biol. 1992, 149, 123-133. [CrossRef] 
50. Yan, H.; Jiao, H.; Liu, Q.; Zhang, Z.; Xiong, Q.; Wang, B.J.; Wang, X.; Guo, M.; Wang, L.F.; Lan, K.; et al. ACE2 receptor usage reveals variation in susceptibility to SARS-CoV and SARS-CoV-2 infection among bat species. Nat. Ecol. Evol. 2021, 5, 600-608. [CrossRef]

51. Liu, K.; Pan, X.; Li, L.; Yu, F.; Zheng, A.; Du, P.; Han, P.; Meng, Y.; Zhang, Y.; Wu, L.; et al. Binding and molecular basis of the bat coronavirus RaTG13 virus to ACE2 in humans and other species. Cell 2021, 184, 3438-3451. [CrossRef] [PubMed]

52. Tan, Y.F.; Teng, C.L.; Chua, K.B.; Voon, K. Pteropine orthoreovirus: An important emerging virus causing infectious disease in the tropics? J. Infect. Dev. Ctries. 2017, 11, 215-219. [CrossRef]

53. Pritchard, L.I.; Chua, K.B.; Cummins, D.; Hyatt, A.; Crameri, G.; Eaton, B.T.; Wang, L.F. Pulau virus; a new member of the Nelson Bay orthoreovirus species isolated from fruit bats in Malaysia. Arch. Virol. 2006, 151, 229-239. [CrossRef]

54. Elbadawy, M.; Usui, T.; Mori, T.; Tsunedomi, R.; Hazama, S.; Nabeta, R.; Uchide, T.; Fukushima, R.; Yoshida, T.; Shibutani, M.; et al. Establishment of a novel experimental model for muscle-invasive bladder cancer using a dog bladder cancer organoid culture. Cancer Sci. 2019, 110, 2806-2821. [CrossRef]

55. Elbadawy, M.; Yamanaka, M.; Goto, Y.; Hayashi, K.; Tsunedomi, R.; Hazama, S.; Nagano, H.; Yoshida, T.; Shibutani, M.; Ichikawa, R.; et al. Efficacy of primary liver organoid culture from different stages of non-alcoholic steatohepatitis (NASH) mouse model. Biomaterials 2020, 237, 119823. [CrossRef] [PubMed]

56. Elbadawy, M.; Hayashi, K.; Ayame, H.; Ishihara, Y.; Abugomaa, A.; Shibutani, M.; Hayashi, S.M.; Hazama, S.; Takenouchi, H.; Nakajima, M.; et al. Anti-cancer activity of amorphous curcumin preparation in patient-derived colorectal cancer organoids. Biomed. Pharmacother. 2021, 142, 112043. [CrossRef]

57. Doi, Y.; Hibino, M.; Hase, R.; Yamamoto, M.; Kasamatsu, Y.; Hirose, M.; Mutoh, Y.; Homma, Y.; Terada, M.; Ogawa, T.; et al. A Prospective, Randomized, Open-Label Trial of Early versus Late Favipiravir Therapy in Hospitalized Patients with COVID-19. Antimicrob. Agents Chemother. 2020, 64, e01897-e01920. [CrossRef]

58. Egawa, K.; Shimojima, M.; Taniguchi, S.; Nagata, N.; Tani, H.; Yoshikawa, T.; Kurosu, T.; Watanabe, S.; Fukushi, S.; Saijo, M. Virulence, pathology, and pathogenesis of Pteropine orthoreovirus (PRV) in BALB/c mice: Development of an animal infection model for PRV. PLoS Negl. Trop. Dis. 2017, 11, e0006076. [CrossRef] [PubMed] 